\title{
BLUEBEARD: EL ARTE DE LA TRANSFORMACIÓN
}

\author{
Jesús Lerate de Castro
}

\begin{abstract}
In the light of the protean nature of Kurt Vonnegut's fictional cosmos, this paper explores this recurrent aspect in Bluebeard, and analyzes some technical devices the author employs to undermine any attempt to understand reality as a stable principle. In this sense, particular attention is paid to the structural juxtaposition of temporal levels, the threefold role of Rabo Karabekian as author-narrator-protagonist, the multiple transformations of the characters, the dynamic tension between Thanatos and Eros, and the dialectic play between the realist and abstract-expressionist aesthetic.
\end{abstract}

Uno de los rasgos más significativos de la narrativa de Kurt Vonnegut es su marcado carácter proteico. En la particular cosmovisión de este novelista no existe ningún significado a priori, ningún principio estable ni permanente. En su mundo imaginativo todo parece ser susceptible de cambio. Como muy acertadamente señala Kathryn Hume, "Vonnegut's fictional cosmos is one of flux and transformation."' Por eso, en las páginas de sus novelas las fronteras entre lo real y lo ficticio tienden a difuminarse. Este proceso de "contaminación" hace posible que en su narrativa confluyan simultáneamente lo autobiográfico y lo creativo, los personajes históricos y los ficticios, las fuentes literarias reales y las inventadas, los coloquialismos y los neologismos. Este incesante juego dinámico - favorecido principalmente por recursos metaficticios como el bricolaje intertextual, las intrusiones autoriales o la "esquizofrénica" espacialización temporalfragmenta la estructura unívoca del texto, y produce resultados artísticos como Slaughterhouse-Five (1969).

Este fragmentarismo afecta también y, de modo muy especial, a la identidad de los personajes, que ven cómo su "yo" se desintegra y se transforma en múltiples "otros." En The Sirens of Titan (1959), la segunda novela del autor, el protagonista se convierte sucesivamente en un lobotizado marciano, en un viajero del espacio y finalmente en un hipnotizado moribundo. En Mother Night (1961) la personalidad esquizofrénica de Howard Campbell le permite trabajar para los nazis y actuar al mismo tiempo como espía de los americanos. En Cat's Cradle (1963), McCabe y Bokonon - como si fueran "full time actors in a play"- se metamorfosean en los papeles que representan. En Breakfast of Champions (1973) todos los personajes, sin excepción, se transforman en marionetas a merced del todo-manipulador Vonnegut. Y en el universo darwinista de Galápagos (1985),

\footnotetext{
${ }^{1}$ Kathyn Hume, "The Heraclitean Cosmos of Kurt Vonnegut" Critical Essays on Kurt Vonnegut. Ed. Robert Merrill (Boston: G.K. Hall, 1990), 216.
} 
los únicos que logran sobrevivir son una especie de mutantes que, adaptándose al medio inhóspito de la Isla de Santa Rosalía, desarrollan aletas, mandíbulas y cráneos pisciformes. Este metamorfismo se aprecia igualmente en el camaleónico personaje de Kilgore Trout -el recurrente alter-ego de Vonnegut- que, a través de sus distintas apariciones literarias, puede ser un "barbudo idealista" (God Bless You, Mr. Rosewater), un "profeta" con aspecto de "prisionèro de guerra" (Slaughterhouse-Five), un viejo "instalador de ventanas" (Breakfast of Champions), un seudónimo literario de Robert Fender (Jailbird) o un fantasma" (Galápagos).

Como muestra esta breve síntesis de su obra literaria, para Vonnegut, como para el poeta romántico Percy B. Shelley, el fundamento estético esencial parece ser que "Naught may endure but Mutability". Esta filosofía artística se evidencia particularmente en Bluebeard (1987), donde el autor socava por medio del arte de la transformación cualquier intento de entender la realidad como un principio absoluto.

En esta su duodécima entrega literaria, se narra de forma calidoscópica la azarosa vida del pintor Rabo Karabekian ${ }^{2}$ desde su nacimiento en San Ignacio (California) en 1916, hasta el verano de 1987, fecha en la que se encuentra escribiendo sus memorias en East Hampton (Long Island). Sin embargo, la novela no sólo es su autobiografía sino "a diary of this past troubled summer, too!" ${ }^{3}$ Este carácter híbrido, que se mantiene a lo largo de toda la obra, le permite a Vonnegut interrelacionar artísticamente el pasado que recuerda Karabekian-autor con hechos y acontecimientos de los que participa en el presente como protagonista. El resultado es una especie de lienzo abstracto-expresionista que representa el autorretrato del autor-protagonista, y que el propio Karabekian, en su rol adicional de narrador, nos explica como si fuera un crítico de arte.

La continua yuxtaposición de planos temporales, con la que ya experimentara Vonnegut en Slaughterhouse-Five, y el papel simultáneo que desempeña este pintor ficticio como autor-narrador-protagonista, genera un dinamismo estructural muy en consonancia con el tema central de la novela. No en vano, Bluebeard desarrolla el proceso de regeneración de Rabo Karabekian a través del arte y la sensibilidad femenina.

Al igual que en Cat's Cradle, el mundo artístico representado en Bluebeard también adquiere fluidez estructural por medio de la tensión dinámica que se establece en la novela entre el principio de Thanatos y Eros y entre la estética realista y la abstracto-expresionista. Este continuo juego dialéctico está íntimamente asociado a tres personajes que son centrales en la vida del protagonista: Dan Gregory, Marilee Kemp y Circe Berman. Mientras que el "demoniaco" Dan Gregory —el famoso pintor realista con el que se inicia

\footnotetext{
${ }^{2}$ Este personaje hace su debut literario en Breakfast of Champions (New York: Delta, 1973). Rabo Karabekian es aqui el autor de un cuadro minimalista titulado The Temptation of Saint Anthony, cuya contemplación le hace ver a un Vonnegut intertextualizado en la narración que no todo es "dead machinery" en el ser humano. Esta "revelación" epifánica, que constituye el climax de la novela, transformará al escritor en "the serene Earthling I am this day" (220).

${ }^{3}$ Kurt Vonnegut, Bluebeard (London: Paladin, 1989), 13. Todas las citas de esta novela están tomadas de esta edición.
} 
el protagonista - diseca y congela la realidad con su arte frío, comercial y representativo, Marilee y Circe representan una fuente de vitalidad y energía creadora para Karabekian. La primera, apartándolo de la esterilidad artística de Gregory e iniciándolo en el sexo y en el arte abstracto. La segunda, animándolo a escribir su autobiografía y a retomar la pintura. A través de estas dos actividades artísticas y del principio de Eros, personificado por Marilee y Circe, el protagonista reconstruirá su pasado y dará sentido a su presente.

Vonnegut también dinamiza y multiplica el mundo ficticio de Bluebeard por medio de las continuas transformaciones que experimentan sus personajes, que bien ocultan, camuflan o cambian de identidad. Así, la madre del protagonista consigue sobrevivir a la masacre turca fingiéndose "dead among the corpses" y su padre, ocultándose "in the shit and piss of a privy behind the schoolhouse where he was a teacher" (15). Rabo Karabekian, por su parte, llega a ser durante la Segunda Guerra Mundial capitán de una unidad especializada en el camuflaje. Dorothy, su primera mujer, convierte de algún modo a Terry y Henri en hijos de Roy, su segundo marido, al cambiarles legalmente el apellido. Dan Gregory, o Gregorian "as he was known in the Old World" (94), puede hacerse pasar por "a movie ganster or cowboy, or a German or Irish or Italian or Swedish immigrant" porque, como dice Karabekian, "Nobody could counterfeit more accents from stage, screen and radio than Dan Gregory" (84-85).

Marilee Kemp es uno de los personajes que más transformaciones experimenta en la novela. Hija de "an illiterate coal miner in West Virginia," se convierte sucesivamente en "Ziegfeld Follies showgirl," "the Countess Portomaggiori, with a pink palace in Florence," "the biggest Sony distributor in Europe, and that old continent's greatest collector of American postwar modern art" (55). La personalidad ambivalente de Marilee Kemp (sugerida por la circunstancia de que posa como Guinevere para una edición ilustrada de Tales of King Arthur and His Knights) se evidencia en el hecho de que es simultáneamente la amante "oficial" de Gregory y la "oficiosa" de Karabekian. La capacidad "camaleónica" de este personaje se materializa incluso a nivel físico. Así, por ejemplo, cuando Karabekian debe encontrarse con Marilee en la estación de autobuses de Nueva York, el protagonista no está seguro de poder reconocerla. Aunque Marilee le ha enviado nueve fotos, éstas parecen ser "pictures of nine different women" (76), ya que en cada una de ellas aparece vestida con un disfraz distinto. Como observa Lawrence Broer, la infinita diversidad de Marilee sugiere el eterno dinamismo de Les Demoiselles d'Avignon de Picasso, en oposición al carácter "monologic of Gregory's own static representations."

Circe Berman, por su parte, se presenta en la mansión de Karabekian haciéndose pasar por una simple escritora aficionada. Pero, de hecho, es una archiconocida autora de novelas para adolescentes que se oculta tras el seudónimo literario de "Polly Madison." Significativamente, además, Paul Slazinger, un amigo de Karabekian, se refiere a ella como "The Homer of the bubblegum crowd" (170). Este apodo sugiere el carácter mitológico y universal de su homónimo en la Odisea, así como la popularidad comercial que tienen sus

\footnotetext{
${ }^{4}$ Lawrence Broer, Sanity Plea, Schizophrenia in the Novels of Kurt Vonnegut. (Ann Arbor: UMI, 1989), 170.
} 
libros entre los jóvenes. A otro nivel, la ambivalencia de Circe se refleja en su papel simbólico de "madre-amante" de Karabekian. En este sentido, Circe no sólo se asemeja físicamente a la madre del protagonista sino que actúa como tal cuando comprensivamente le insta a que le hable de la muerte de sus padres: "sit down here and tell Mama how your parents died" (23). Paralelamente, Circe parece compaginar este papel maternal con el de amante èspiritual de Karabekian: "although we had not and never would make love, our moods were postcoital" (254).

Pero Circe Berman no es el único personaje que simultanea varios papeles a la vez. En la novela encontramos otros personajes menores que también participan de este metamorfismo. La cocinera de Gregory “wasn't just a woman, and she wasn't just a man, either. She was somewhat both. She was a hermaphrodite" (128); Sam Wu, por su parte, es un "simperingly polite laundryman," pero también el modelo que le sirve a Gregory para ilustrar "the master criminal Fu Manchu" (86); y el Conde Bruno Portomaggiore -el "marido homosexual" de Marilee- será víctima de su doble actividad como espía británico y Ministro de Cultura de Mussolini.

En Bluebeard los cambios y transformaciones no sólo afectan a los personajes, sino también a todo lo que generalmente se considera estable y permanente. Así, por ejemplo, Karabekian descubre en una visita a Nueva York que la casa de Gregory es ahora "the Delegation to the United Nations of the Emirate of Salibaar" (100). Este emirato, como el misterioso país de Uqbar en la historia de Borges, no figura en la prestigiosa Encyclopaedia Britannica que consulta Karabekian, y este hecho sugiere cuando menos la dudosa existencia de Salibaar.

Làs obras de arte también experimentan cambios notables. Así, el monje dominico Girolamo Savonarola borra todo vestigio pagano de los frescos del palacio de los Medicis para transformarlos en murales cristianos. Un caso inverso de transformación se da cuando Picasso "mutila" un poster de Gregory para crear con los trozos sueltos el artístico collage de un gato.

Pero en la novela la transformación artística más importante es la que experimenta el último cuadro de Karabekian titulado Now It's the Women's Turn. Este cuadro, "so realistic that it might have been a photograph" (240), está pintado sobre la superficie de lo que en otro tiempo fuera un cuadro abstracto-expresionista llamado Windsor Blue Number Seventeen y que a causa de una extraña reacción química producida por la pintura empleada se ha borrado completamente. Para William R. Allen, este hecho evidenciaría la vuelta de Karabekian a la estética realista al final de su vida, también explicaría el subtítulo de la novela - "Confessions of an Armenian Late Bloomer or Always the Last to Learn" (168) - y simbolizaría, además, la evolución narrativa de Vonnegut hacia el neorrealismo. ${ }^{5}$ En mi opinión esta interpretación es desafortunada y desvirtua el significado esencial de la obra. La evolución de Karabekian hacia el realismo "petrificado" de Gregory es más aparente que real. Como él mismo dice: "One would soon go mad if one took such

\footnotetext{
${ }^{5}$ Véase William R. Allen, Understanding Kurt Vonnegut (Columbia: U of South Carolina P, 1991), 11.
} 
coincidences too seriously" (186). Pero no sólo esto, también resultaría inconsistente con los propios principios estéticos de Karabekian y su forma de entender la realidad. Sin duda, el que Windsor Blue Number Seventeen se convierta en Now It's Women's Turn implica un cambio, pero no necesariamente estético sino más bien emocional. La obra maestra de Karabekian es como su autobiografía: un montaje o collage abstracto que muestra visualmente la propia reconstrucción psíquica del protagonista. En este sentido, Now It's Women's Turn sería una representación pictórica de lo que nos cuentan las páginas del libro. De este modo, literatura y pintura servirían el mismo propósito: proporcionarle a Karabekian la posibilidad de reunificar su realidad fragmentada.

Ilustrando literariamente su teoría de que el tiempo es "líquido" y que "life is never still," las experiencias pasadas y presentes de Karabekian se entrecruzan continuamente en la narración, hasta el punto de dar la impresión de que el protagonista está tan "unstuck in time" como Billy Pilgrim en Slaughterhouse-Five. Esta movilidad se aprecia también en la pintura abstracta. Como dice Karabekian: "I lay on the first stroke of color. After that, the canvas has to do at least half the work" (149). Este carácter dinámico y fluido queda reflejado igualmente en Now It's the Women's Turn. En efecto, el cuadro de Karabekian como su autobiografía - está lleno de hombres y mujeres víctimas de la crueldad de la guerra, hay supervivientes de campos de concentración, lunáticos, artistas y soldados. La imagen devastadora que se desprende del cuadro es idéntica a la que describe Vonnegut en Slaughterhouse-Five o la que plasma Picasso en su Guernica. Al igual que estas obras, el cuadro de Karabekian trata sobre la guerra, pero es al mismo tiempo un grito en contra de la crueldad de ésta. Por eso, en Now It's the Women's Turn también hay "healthy women" (Marilee y Circe) que, como fuerzas dinámicas y regeneradoras en la vida del protagonista, están estratégicamente situadas "in the corners at the bottom" (243), mientras que lo que "might be taken for the soul of Rabo Karabekian" (242) aparece representado en el centro del cuadro.

Como reflexión final, puede decirse que Bluebeard explora el proceso de reconstrucción emocional de Karabekian a través del arte (literatura y pintura) y la sensibilidad femenina (amor). Este proceso llevará al protagonista a superar la muerte de sus padres, la Gran Depresión, la Segunda Guerra Mundial, su fracaso matrimonial con Dorothy, la pérdida de Edith - su segunda esposa-, el suicidio de sus amigos pintores y, finalmente, su propia apatía creativa. Pero este proceso de superación emocional no está desarrollado ni narrativamente (en su autobiografía) ni pictóricamente (en Now It's the Women's Turn) de forma lineal, sino más bien con la fluidez dinámica que caracteriza al arte abstracto. Por medio del arte de la transformación, Vonnegut consigue que realidad y ficción se sincreticen, que la imaginación pueda crear la realidad y que, en definitiva, sea cada lector el que reconstruya — como hace el mismo protagonista— la vida de Rabo Karabekian. 